\title{
BMJ Open Influencing factors of dysmenorrhoea among hospital nurses: a questionnaire survey in Taiwan
}

\author{
Min-Hui Chiu, ${ }^{1,2}$ Hsiu-Fen Hsieh, ${ }^{1}$ Yi-Hsin Yang, ${ }^{3}$ Huei-Mein Chen, ${ }^{4}$ Su-Chen Hsu, ${ }^{2}$ \\ Hsiu-Hung Wang ${ }^{1}$
}

To cite: Chiu M-H, Hsieh H-F, Yang $\mathrm{Y}-\mathrm{H}$, et al. Influencing factors of dysmenorrhoea among hospital nurses: a questionnaire survey in Taiwan. BMJ Open 2017;7:e017615. doi:10.1136/ bmjopen-2017-017615

- Prepublication history for this paper is available online. To view these files, please visit the journal online (http://dx.doi org/10.1136/bmjopen-2017017615).

Received 4 May 2017 Revised 15 November 2017 Accepted 17 November 2017

\section{CrossMark}

${ }^{1}$ College of Nursing, Kaohsiung Medical University, Kaohsiung, Taiwan

${ }^{2}$ Chi Mei Medical Centre, Liouying, Tainan, Taiwan

${ }^{3}$ College of Pharmacy, Kaohsiung Medical University, Kaohsiung,

Taiwan

${ }^{4}$ College of Nursing, Chung Hwa University of Medical Technology, Tainan, Taiwan

Correspondence to Professor Hsiu-Hung Wang; hhwang@kmu.edu.tw

\section{ABSTRACT}

Objectives Nurses are at high risk of dysmenorrhoea while working with patients. The study objectives were to: (1) describe the demographic and menstruation characteristics of dysmenorrhoea, knowledge about dysmenorrhoea and menstrual attitudes towards menstruation among dysmenorrhoeal and nondysmenorrhoeal hospital nurses; (2) identify significant differences between the groups; and (3) examine factors influencing dysmenorrhoea.

Methods This cross-sectional survey used a structured questionnaire, administered at two hospitals in southern Taiwan. Participants included hospital nurses at least 18 years of age who agreed to participate. All participants were recruited through random sampling. The questionnaire included demographic data, the Dysmenorrhoea Knowledge Scale and Menstrual Attitude Scale (MAS).

Results A total of 420 nurses completed the questionnaire. Among them, 297 (70.7\%) had experienced dysmenorrhoea in the past 6 months and 123 (29.3\%) had not. Significant differences in age $(\mathrm{P}<0.001)$, marital status $(P<0.001)$, childbearing status $(P<0.001)$, age at menarche $(P<0.05)$ and rotating three shift ratio $(P<0.05)$ were identified between the dysmenorrhoea and nondysmenorrhoea groups. Analysis of the MAS results revealed significant differences between the groups regarding consideration of menstruation as a debilitating $(P<0.001)$ or bothersome event $(P<0.05)$, anticipation and prediction of menstruation onset $(\mathrm{P}<0.01)$ and denial of any effects from menstruation $(P<0.001)$. Results of the multiple logistic regression showed that predictive factors included age $<40$ years (4.46 vs 1.00 ), working three shift rotations ( 2.07 vs 1.00 ), marital status ( 2.59 vs 1.00 ), acknowledging menstruation as a debilitating event $(2.72$ vs 1.00 ) and denial of effects from menstruation (2.59 vs 1.00).

Conclusions These findings could help nursing managers to create a caring and friendly work environment for hospital nurses at risk of dysmenorrhoea.

\section{INTRODUCTION}

More than $50 \%$ of women experience dysmenorrhoea, defined as pain that accompanies menstruation. The majority $(75.1 \%)$ of women believe dysmenorrhoea to be a normal part of their lives and that the

\section{Strengths and limitations of this study}

The factors influencing dysmenorrhoea are complex; in this study, multiple logistic regression analysis was used to control for confounding variables and to identify these factors.

- Participants in this study were aged 22-48 years; therefore, the results have limited application to hospital nurses aged $<22$ years and $>48$ years.

- This study was limited in terms of analysing the effects of lifestyle choices, such as smoking and alcohol consumption, because only a few nurses reported these behaviours.

symptoms will continue to affect their daily life until they near menopause. ${ }^{1}$ Dysmenorrhoea occurs during the first 1-3 years after menarche and is commonly accompanied by sweating, lack of appetite, headache, distraction, nausea, vomiting, dizziness ${ }^{2}$ and depression. ${ }^{3}$ Dysmenorrhoea arises during menstrual bleeding owing to lower abdominal pain brought on by menses, and is not a gynaecological disorder. ${ }^{4}$ The prevalence rates of dysmenorrhoea differ by age; however, more than $50 \%$ of women in all age groups experience dysmenorrhoea. The prevalence rate of dysmenorrhoea worldwide is between $50.9 \%$ and $87.4 \% .{ }^{5-7}$ Parker et al found that $21 \%$ of Australian adolescents experienced severe dysmenorrhoea, with $26 \%$ requiring absence from school. ${ }^{8}$

In Taiwan, the reported prevalence rate of dysmenorrhoea among adolescent vocational nursing students aged $16-18$ years was $73.3 \%{ }^{9}$; another study reported a prevalence rate of $90.2 \%$ among the general population of women in Taiwan. ${ }^{10}$ A study in hospital nurses in Taiwan reported a prevalence rate of $90.7 \% .^{11}$ Despite the high prevalence of dysmenorrhoea, nurses often neglect their own health while working and caring for patients. $^{12}$ 
Dysmenorrhoea can be cyclical or chronic; in some cases, it can be a result of pain catastrophising and anxiety sensitivity. ${ }^{13}$ Dysmenorrhoea not only causes physical pain, it also affects mental well being and quality of life, leading to work or school absenteeism and a significant health burden. ${ }^{14-18}$ Despite its high prevalence rate and effect on daily life, $76.1 \%$ of women still believe that dysmenorrhoea is a natural part of a women's menstrual cycle, and only $14.8 \%$ believe that treatment is necessary. ${ }^{16} \mathrm{In}$ terms of dysmenorrhoea information, $62.3 \%$ of adolescent girls claim that they learnt about the condition from their mothers, and $52.9 \%$ state that they obtained their knowledge from peers. ${ }^{16}$ In addition, dysmenorrhoea is negatively correlated with self-awareness of one's own health; in other words, individuals with dysmenorrhoea have poorer self-awareness regarding their own health. ${ }^{6}$

A study of 297 nurses (average age 30.3 years) revealed that $8.4 \%$ had taken menstrual leave, $11.8 \%$ had taken a leave of absence for dysmenorrhoea and $28.6 \%$ saw their doctors owing to the condition. ${ }^{15}$ Furthermore, 20.8\% of adolescent girls from vocational schools in the same region had visited doctors for consultation regarding dysmenorrhoea. ${ }^{9}$ Menstrual leave is currently available in Japan, Indonesia, South Korea and Taiwan. Focus group studies in Taiwan have shown that most women have experienced menstrual discomfort and that they understand the implementation and regulation of menstrual leave in different companies. However, in reality, menstrual leave is rarely availed of owing to the following factors: 'the regulations are too rigid,' 'no one else has taken menstrual leave,' 'other kinds of leave are available,' 'no one will take my shift' or 'there has to be a doctor's note'. ${ }^{19}$

Previous studies have shown that the physical and mental health of nurses is significantly correlated with job satisfaction, tiredness and comfort. ${ }^{19}{ }^{20}$ The Gender Equality in Employment Act of Taiwan, approved in 2002, clearly defines the regulations regarding menstrual leave, in which a female employee who has trouble working due to discomfort during menstruation should take 1 day of menstrual leave every month. ${ }^{21}$ However, because of the particularities of nursing, temporary leave affects the allocation of nurses. Cheng found that the long term use of medication to maintain a ready to work status is common among women. Nurses, who have frequent contact with drugs, use them extensively to overcome menstrual discomfort at work, ${ }^{10}$ including the use of sumatriptannaproxen sodium to reduce the effects of dysmenorrhoea during work and leisure. ${ }^{212}$

Several risk factors affect dysmenorrhoea. (a) Age: older women are generally less likely to experience dysmenorrhoea, although the relationships with marital status or childbirth history remain unclear. (b) Age at menarche: age at menarche is significantly related to the occurrence of dysmenorrhoea, and women who demonstrate an earlier age at menarche are more likely to experience more severe dysmenorrhoea. ${ }^{7}{ }^{17}$ (c) Duration of menstrual cycle: a Nigerian study noted that longer menstrual flow duration is an important predictive factor of dysmenorrhoea. ${ }^{7}$ (d) Regularity of menstrual cycle: women with irregular menstrual cycles are more likely to have dysmenorrhoea. ${ }^{9}$ In terms of lifestyle factors, the results of several studies indicate that smoking and alcohol consumption are risk factors for primary dysmenorrhoea and that women who habitually smoke or drink alcohol are more likely to have dysmenorrhoea. ${ }^{23}{ }^{24}$ With regards to work, several studies have found that women who work rotations, especially nurses who have to alternate between day and night shifts, experience relatively more serious menstrual discomfort. ${ }^{21}$ Nurses who work night shifts are more likely to experience dysmenorrhoeal symptoms during their menstrual cycles than those who work regular shifts. ${ }^{15}$

Furthermore, the attitudes of adolescent students toward menstruation correlate with the occurrence of dysmenorrhoea. ${ }^{25}$ Adolescent girls who tend to feel that menstruation is a debilitating experience and those who anticipate and predict the onset of menstruation are more likely to experience dysmenorrhoea. ${ }^{26}$ The effect of dysmenorrhoea on women varies based on the degree and frequency of their pain.

Previous studies have revealed that women have inadequate knowledge about menstruation, and that educational information about menstrual healthcare contains contradictory messages, including the idea that menstruation is a normal and natural event but should be 'invisible'. ${ }^{27}$ Cheng observed that some female students knew about menstruation taboos; although they had doubts about these taboos, they still had negative attitudes towards menstruation. ${ }^{28}$ Medical expenses due to dysmenorrhoea increase with age; therefore, the topic of women's menstrual health and accompanying emotional challenges should be taken seriously. ${ }^{29}$ Nevertheless, because dysmenorrhoea is so common, many women consider it a natural phenomenon and rarely seek medical treatment owing to their cultural and religious attitudes ${ }^{15}$ or because they feel that they can tolerate the pain. ${ }^{23}$

Herein we defined dysmenorrhoea as lower abdominal pain brought on by menses at any time during the past 6 months. ${ }^{11}$ In Taiwan, $98.8 \%$ of hospital nurses are women. There is a high prevalence rate of dysmenorrhoea among women. Owing to the nature of nursing work, nurses are at high risk of dysmenorrhoea. However, previous relevant studies on nurses have not discussed the factors influencing dysmenorrhoea.

The objectives of this study were to: (1) describe the basic demographic data as well as menstruation characteristics of dysmenorrhoea, knowledge of dysmenorrhoea and attitudes towards menstruation among dysmenorrhoeal and non-dysmenorrhoeal clinical nurses; (2) analyse the demographic data as well as the menstruation characteristics, knowledge about dysmenorrhoea and attitudes towards menstruation among dysmenorrhoeal and non-dysmenorrhoeal clinical nurses, and identify significant differences between these groups; and (3) examine the risk factors for dysmenorrhoea among clinical nurses. 


\section{METHODS}

\section{Study design and participants}

The study used a cross sectional survey based on structured questionnaires for data collection. Participants were recruited from two medical institutions in southern Taiwan; one institution was a medical centre with 1300 beds, the other was a regional hospital with 650 beds. The two institutions were at different hospital levels within the same healthcare system. All 2000 nurses at the two institutions were potential participants. The inclusion criteria for this study were full time nurses employed at the study hospitals who were at least 18 years of age and agreed to participate in the study after providing informed consent. The sample size was estimated using JMP 7.0 (SAS Institute, Cary, North Carolina, USA) with an effect size of $0.3, \alpha$ of 0.05 and a power of 0.80 , resulting in a required sample size of 350 individuals. With a predicted questionnaire recovery rate of $80 \%$, the sample size was estimated to be 438. After obtaining a list of the names of the potential participants, serial numbers were assigned to each participant. The estimated number of study participants was randomly selected using the sampling function of Microsoft Excel 2007. In total, 450 nurses were chosen for inclusion in the study, and 420 valid questionnaires were returned, yielding a response rate of $93.3 \%$. Among these 420 nurses, 297 (70.7\%) had experienced dysmenorrhoea in the past 6 months and were classified as the dysmenorrhoea group; 123 (29.3\%) nurses who had not experienced dysmenorrhoea were classified as the non-dysmenorrhoea group.

The random sampling was conducted after the study received approval from the Institutional Review Boards (IRBD No CLH0088) of the two hospitals. The questionnaires were administered to the nurses by a trained research assistant. All participants provided their written consent and answered the questionnaires independently. The written consent form indicated that participation in this study was not compulsory and the questionnaire was anonymous. Anyone who was not willing to participate in the study could simply choose not to return the questionnaire. No individual rights or interests were compromised during this process. Those who completed the questionnaire received a small gift. The questionnaires were collected 2 weeks after being issued. The written consent forms and questionnaires were filed separately and placed in locations chosen by participants, to protect their personal privacy.

\section{Measurements}

This study was conducted in May 2010. The study instruments included the Demographic Inventory (DI), Dysmenorrhoeal Knowledge Scale (DKS) and Menstrual Attitude Scale (MAS). The DI was designed based on related studies ${ }^{930}$ and included age, age at menarche, marital and childbirth status, discussion of menstrual hygiene, dysmenorrhoea experience, medical experience of dysmenorrhoea, working conditions, self-care health education regarding menstruation, factors affecting dysmenorrhoea and work coping methods. The DKS was designed using both the researchers' clinical experiences and previous studies. ${ }^{30}$ The scale included 20 questions with yes/no answers, for example, 'Women with dysmenorrhoea are at high risk for sterility' and 'Applying hot compresses to the lower abdomen can ease menstrual cramps'. Correct answers received a score of 1 and incorrect answers a score of 0 . The total summed scores ranged from 0 to 20, with higher scores representing better knowledge of dysmenorrhoea. The Kuder-Richardson reliability coefficient was 0.63 , according to a previous study, ${ }^{30}$ and 0.72 in this study.

The MAS was developed by Brooks-Gunn and Ruble $(1980)^{31}$ and modified by Lee (1994). Lee translated this scale into a Chinese version and deleted one item owing to cultural differences. ${ }^{32}$ The Chinese version of the MAS has 32 items with five dimensions, including consideration of menstruation as a debilitating event, menstruation as a bothersome event, menstruation as a natural event, anticipation and prediction of the onset of menstruation, and denial of the effects of menstruation. Each item is scored on a 7 point Likert scale from 1 (strongly disagree) to 7 (strongly agree). The total summed scores range from 32 to 224, with higher scores representing a more positive attitude toward menstruation. Cronbach's $\alpha$ was 0.58 in the original scale ${ }^{31}$ and 0.61 in Morrison's study. ${ }^{33}$ Lo and Lin suggested that an acceptable Cronbach's $\alpha$ range is $0.3-0.7 .{ }^{34}$ Because we were concerned about the comparability of our study with other studies, we decided to use this scale with a Cronbach's $\alpha$ of 0.57 in the present study.

\section{Data analysis}

The data in this study were entered using Microsoft Excel. JMP 7.0 was used for the statistical analysis. Based on the study variables and objectives, percentages, mean and SD were used to describe participant demographics and menstruation characteristics as well as DKS and MAS score distributions in the dysmenorrhoea and non-dysmenorrhoea groups. We used $\mathrm{t}$ tests and $\chi^{2}$ tests to detect differences in demographics, menstruation characteristics, DKS score and MAS score between the two groups. Finally, multiple logistic regression analysis was used to examine factors (independent variables) influencing the occurrence of dysmenorrhoea (dependent variable). Independent variables with significant differences were included in the multiple logistic regression analysis.

\section{RESULTS}

A total of 420 participants completed the questionnaire. Among them, 297 (70.7\%) had experienced dysmenorrhoea in the past 6 months and $123(29.3 \%)$ had not. Compared with the non-dysmenorrhoea group, participants with dysmenorrhoea were significantly younger $(\mathrm{t}=-3.78, \mathrm{P}<0.001)$, were more frequently unmarried $\left(77.78 \%, \chi^{2}=20.03, \mathrm{P}<0.001\right)$ with no history of childbirth $\left(83.16 \%, \chi^{2}=19.38, \quad \mathrm{P}<0.001\right)$, and more often demonstrated an age at menarche of $<12$ years $(15.49 \%$, 
$\left.\chi^{2}=4.70, \quad \mathrm{P}=0.03\right)$; moreover, a higher percentage of participants with dysmenorrhoea worked a three shift rotation $\left(91.25 \%, \chi^{2}=6.06, \mathrm{P}=0.014\right)$. The other variables showed no significant differences between the two groups (table 1).

With respect to knowledge about dysmenorrhoea, there was a non-significant difference between the two groups $(\mathrm{P}=0.238)$. The highest scoring items among both groups were 'applying hot compresses', 'adopting a knee to chest position' and 'drinking hot beverages including warm water or milk or ginger soup to ease cramps'. The lowest scoring items were 'normal bleeding amount every cycle', 'dysmenorrhoea is a disease of the reproductive system' and 'women with dysmenorrhoea are at high risk for sterility'. Regarding attitudes towards menstruation, after standardising, the highest scoring dimension among the dysmenorrhoea group was 'considering menstruation a debilitating event' (73.30) and 'considering menstruation a natural event' (74.93) in the non-dysmenorrhoea group. The lowest scoring dimension in both groups was 'denial of any effect of menstruation' (47.18 in the dysmenorrhoea group and 54.69 in the dysmenorrhoea group). Women who experienced dysmenorrhoea had significantly higher scores than women in the non-dysmenorrhoea group with respect to the following: considering menstruation a debilitating event $(\mathrm{P}<0.001)$, considering menstruation a bothersome event $(\mathrm{P}=0.024)$, and anticipation and prediction of menstruation onset $(\mathrm{P}=0.004)$. In terms of denying the effects of menstruation, scores for the dysmenorrhoea group were significantly lower than those of the non-dysmenorrhoea group $(\mathrm{P}<0.001)$. No significant differences were observed between the groups in terms of considering menstruation a natural event (table 2).

We conducted a multiple logistic regression analysis using dysmenorrhoea and non-dysmenorrhoea as dependent variables, which yielded significant differences in the variables of demographics, menstruation characteristics, DKS score and MAS score between the two groups. The results of the analysis showed that crucial predictive factors for the occurrence of dysmenorrhoea among hospital nurses included age $<40$ years, working three shift rotations and marital status. Moreover, using the mean as the contact point, we found that the tendency to consider menstruation to be a debilitating event and the tendency to deny the effects of menstruation were also predictive factors for dysmenorrhoea occurrence. The adjusted odd ratios are shown in table 3 .

After controlling for working three shift rotations, marital status, the tendency to consider menstruation a debilitating event and the tendency to deny the effects of menstruation, the rate of occurrence of dysmenorrhoea in women younger than 40 years was 4.46 times higher than that in women over 40 years of age. After controlling for age, marital status, the tendency to consider menstruation a debilitating event and tendency to deny the effects of menstruation, the rate of occurrence of dysmenorrhoea among nurses who worked three shift rotations was 2.07 times higher than that in nurses who did not. After controlling for age, working three shift rotations, marital status and the tendency to deny the effects of menstruation, participants who felt that menstruation was a debilitating event had a dysmenorrhoea occurrence rate that was 2.72 times higher than that of participants who did not. After controlling for age, working three shift rotations, marital status and the tendency to think of menstruation as a debilitating event, women who did not acknowledge the effects of menstruation had a dysmenorrhoea occurrence rate that was 2.59 times higher than that in women who did not deny these effects.

\section{DISCUSSION}

Although the average age of participants in the dysmenorrhoea group was significantly lower than that of women in the non-dysmenorrhoea group, when age was the only variable being compared, the dysmenorrhoea occurrence rate among nurses younger than 40 years was 4.06 times higher than that of nurses aged over age 40 years; after controlling for confounding variables, the rate of dysmenorrhoea in younger women was 4.46 times higher than that in women over 40 years old. Therefore, age was a risk factor for dysmenorrhoea. To our knowledge, no other studies have directly discussed the correlation between age and dysmenorrhoea. However, previous studies have reported dysmenorrhoea occurrence rates over $76 \%$ in adolescent girls or students, ${ }^{5616}$ and another reported a rate of $55.9 \%$ among women aged $15-45$ years,${ }^{31}$ wherein a decrease in the occurrence of dysmenorrhoea with increasing age was observed. As dysmenorrhoea is very common, periodic dysmenorrhoea is a natural phenomenon observed during the menstrual cycle. With age, the number of episodes of dysmenorrhoea and the number of times coping strategies were used among women also increased; therefore, women with dysmenorrhoea can be thought of as 'female specialists with embodied knowledge', meaning that their experiences may affect their subjective perception and tolerance of dysmenorrhoea, which can in turn affect the occurrence of dysmenorrhoea. ${ }^{35}$ Nursing is a female dominated occupation in Taiwan. In this study, $97 \%$ of participants were younger than 40 years. The high prevalence rate of dysmenorrhoea severely affects nurses such that they may not be able to focus on their work, thereby affecting the quality of patient care. Nurses may need to take menstrual leave, which can cause a shortage of nursing resources.

In terms of marital status, the ratio of unmarried to married women in the dysmenorrhoea group was 2.74 times that of the non-dysmenorrhoea group, indicating a high dysmenorrhoea occurrence rate among unmarried women; after adjusting for confounding variables, it was 2.59 times higher than that among married women. This result is consistent with those of Chung (average study participant age 27 years), who reported a higher dysmenorrhoea occurrence rate in single nurses than in married 
Table 1 Comparison of demographic and menstruation characteristics between the dysmenorrhoea and non-dysmenorrhoea groups

\begin{tabular}{|c|c|c|c|c|c|c|}
\hline & $\begin{array}{l}\text { Dysmenorrh } \\
(\mathrm{n}=297)\end{array}$ & eal group & $\begin{array}{l}\text { Non-dysmen } \\
(n=123)\end{array}$ & eal group & & \\
\hline Variable & $\mathrm{n}$ & $\%$ & $\mathrm{n}$ & $\%$ & $\operatorname{tor} \chi^{2}$ & $P$ value \\
\hline Age (years) (mean $\pm S D$ ) & $30.33 \pm 3.61$ & & $32.04 \pm 4.47$ & & -3.78 & $<0.001$ \\
\hline Age $<40$ & 292 & 98.32 & 115 & 93.50 & 6.74 & $<0.01$ \\
\hline Age $\geq 40$ & 5 & 1.68 & 8 & 6.50 & & \\
\hline Marital status & & & & & 20.03 & $<0.001$ \\
\hline Unmarried & 231 & 77.78 & 69 & 56.10 & & \\
\hline Married & 66 & 22.22 & 54 & 43.90 & & \\
\hline Childbearing & & & & & 19.38 & $<0.001$ \\
\hline No & 247 & 83.16 & 78 & 63.41 & & \\
\hline Yes & 50 & 16.84 & 45 & 36.59 & & \\
\hline Age of menarche (years) & & & & & 4.70 & 0.030 \\
\hline$>12$ & 46 & 15.49 & 11 & 8.94 & & \\
\hline$\geq 12$ & 251 & 84.51 & 112 & 91.06 & & \\
\hline Regularity of menstrual cycle & & & & & 0.10 & 0.755 \\
\hline Yes & 193 & 64.98 & 85 & 69.11 & & \\
\hline No & 104 & 35.02 & 38 & 30.89 & & \\
\hline Duration of menstrual cycle (days) & & & & & 1.99 & 0.575 \\
\hline$\leq 4$ & 110 & 37.04 & 43 & 34.96 & & \\
\hline $5-6$ & 157 & 52.86 & 70 & 56.91 & & \\
\hline$\geq 7$ & 30 & 10.10 & 10 & 8.13 & & \\
\hline $\begin{array}{l}\text { Prior health education on } \\
\text { dysmenorrhoea }\end{array}$ & & & & & 0.99 & 0.321 \\
\hline No & 163 & 54.88 & 74 & 60.16 & & \\
\hline Yes & 134 & 45.12 & 49 & 39.84 & & \\
\hline Three shift rotation & & & & & 6.06 & 0.014 \\
\hline Yes & 271 & 91.25 & 102 & 82.93 & & \\
\hline No & 26 & 8.75 & 21 & 17.07 & & \\
\hline $\begin{array}{l}\text { Do you know you can ask for menstrual } \\
\text { leave? }\end{array}$ & & & & & 2.03 & 0.154 \\
\hline Yes & 242 & 81.48 & 107 & 86.99 & & \\
\hline No & 55 & 18.52 & 16 & 13.01 & & \\
\hline $\begin{array}{l}\text { Do you consider menstrual leave } \\
\text { necessary? }\end{array}$ & & & & & 1.68 & 0.195 \\
\hline Yes & 288 & 96.97 & 115 & 93.50 & & \\
\hline No & 9 & 3.03 & 8 & 6.50 & & \\
\hline $\begin{array}{l}\text { Have you ever asked for menstrual } \\
\text { leave? }\end{array}$ & & & & & 0.14 & 0.707 \\
\hline No & 272 & 91.58 & 114 & 92.68 & & \\
\hline Yes & 25 & 8.42 & 9 & 7.32 & & \\
\hline $\begin{array}{l}\text { Have you ever asked for more leave for } \\
\text { dysmenorrhoea? }\end{array}$ & & & & & 3.59 & 0.058 \\
\hline No & 262 & 88.22 & 116 & 94.31 & & \\
\hline Yes & 35 & 11.78 & 7 & 5.69 & & \\
\hline Secondary dysmenorrhoea & & & & & 0.02 & 0.886 \\
\hline No & 267 & 89.90 & 110 & 89.43 & & \\
\hline Yes & 30 & 10.10 & 13 & 10.57 & & \\
\hline
\end{tabular}

Note, regularity of periods indicates that the duration between consecutive first day menses is similar. 
Table 2 Comparison of dysmenorrhoeic knowledge and attitudes towards menstruation between the dysmenorrhoea and non-dysmenorrhoea groups

\begin{tabular}{|c|c|c|c|c|c|c|}
\hline \multirow[b]{2}{*}{ Variable } & \multicolumn{2}{|c|}{$\begin{array}{l}\text { Dysmenorrhoeal group } \\
(\mathrm{n}=297)\end{array}$} & \multicolumn{2}{|c|}{$\begin{array}{l}\text { Non-dysmenorrhoeal group } \\
(n=123)\end{array}$} & \multirow{2}{*}{ t value } & \multirow[b]{2}{*}{$P$ value } \\
\hline & Mean & SD & Mean & SD & & \\
\hline Dysmenorrhoeic Knowledge Scale & 14.12 & 2.19 & 13.40 & 2.40 & 1.18 & 0.238 \\
\hline Menstrual Attitude Scale & 148.64 & 12.74 & 146.85 & 12.69 & 1.31 & 0.192 \\
\hline Menstruation as a debilitating event & 56.44 & 8.52 & 52.55 & 7.65 & 4.58 & $<0.001$ \\
\hline Menstruation as a bothersome event & 29.05 & 5.01 & 27.54 & 6.64 & 2.27 & 0.024 \\
\hline Menstruation as a natural event & 19.98 & 5.19 & 20.98 & 4.92 & -1.87 & 0.062 \\
\hline $\begin{array}{l}\text { Anticipation and prediction of the onset of } \\
\text { menstruation }\end{array}$ & 20.04 & 3.01 & 18.98 & 3.55 & 2.93 & 0.004 \\
\hline Denial of any effect of menstruation & 23.12 & 6.75 & 26.80 & 5.70 & 5.70 & $<0.001$ \\
\hline
\end{tabular}

and divorced ones. ${ }^{36}$ Many women are told by their doctors that their dysmenorrhoea will improve after getting married and giving birth, which may improve menstrual blood discharge. Furthermore, women may engage in positive self-care for menstruation after getting married for childbearing reasons, which may also be a factor that indirectly relieves dysmenorrhoea. ${ }^{11}$ In terms of work, the dysmenorrhoea occurrence rate among nurses in the dysmenorrhoea group who worked three shift rotations was 2.15 times that of nurses in the non-dysmenorrhoea group; after adjusting for confounding variables, it was 2.07 times higher than among nurses who did not work three shift rotations. This indicates that work type (eg, rotating nightshifts) is a risk factor for dysmenorrhoea in nurses. However, Chung found that rotating work shifts were not significantly related to dysmenorrhoea occurrence in nurses. ${ }^{36}$ Furthermore, one study among Japanese junior high school students also found that nightshift work was not significantly associated with dysmenorrhoea. $^{37}$ However, focus group interviews conducted by Chang revealed that working rotating shifts was highly associated with menstrual discomfort. ${ }^{19}$ Owing to the nature of nursing work, most nurses need to work rotating night shifts, and the graveyard shift can easily cause uncomfortable menstrual cycles or obvious irregularities. ${ }^{25}$ Owing to nurses' day/night activities and sleep patterns, along with the increased pressure of working night shifts, menstrual discomfort may be more common in those with frequent rotation changes.

In terms of attitudes towards menstruation, the dysmenorrhoea group had significantly higher scores than the non-dysmenorrhoea group in terms of considering

\begin{tabular}{|c|c|c|c|c|c|c|}
\hline & $\begin{array}{l}\text { Crude } \\
\text { OR }\end{array}$ & $95 \% \mathrm{Cl}$ & $P$ value & $\begin{array}{l}\text { Adjusted } \\
\text { OR }\end{array}$ & $95 \% \mathrm{Cl}$ & $P$ value \\
\hline \multicolumn{7}{|l|}{ Age (years) } \\
\hline Age $>40$ & 4.06 & (1.33 to 13.7$)$ & $>0.05$ & 4.46 & (1.24 to 17.23$)$ & $>0.05$ \\
\hline Age $\geq 40$ & 1.00 & - & & 1.00 & - & \\
\hline \multicolumn{7}{|c|}{ Three shift rotation } \\
\hline Yes & 2.15 & (1.15 to 3.98$)$ & $>0.05$ & 2.07 & (1.01 to 4.21$)$ & $>0.05$ \\
\hline No & 1.00 & - & & 1.00 & - & \\
\hline \multicolumn{7}{|l|}{ Married } \\
\hline No & 2.74 & (1.75 to 4.30$)$ & $<0.001$ & 2.59 & (1.57 to 4.28$)$ & $<0.001$ \\
\hline Yes & 1.00 & - & & 1.00 & - & \\
\hline \multicolumn{7}{|c|}{ Menstruation as a debilitating event } \\
\hline Higher & 2.53 & (1.63 to 3.95$)$ & $<0.001$ & 2.72 & (1.67 to 4.52$)$ & $<0.001$ \\
\hline Lower & 1.00 & - & & 1.00 & - & \\
\hline \multicolumn{7}{|c|}{ Denial of any effect of menstruation } \\
\hline Lower & 2.83 & (1.83 to 4.46$)$ & $<0.001$ & 2.59 & (1.61 to 4.23 ) & $<0.001$ \\
\hline Higher & 1.00 & - & & 1.00 & - & \\
\hline
\end{tabular}

Reference group: age $\geq 40$ years, no three shift rotation, unmarried, reduced menstruation as a debilitating event and increased denial of any effect on menstruation. 
menstruation to be a debilitating event, and significantly lower scores than the non-dysmenorrhoea group in terms of denying the effects of menstruation. In the multiple logistic regression analysis of attitudes towards menstruation, the tendency to consider menstruation as a debilitating event in the dysmenorrhoea group was 2.53 times higher than that in the non-dysmenorrhoea group; after adjusting for confounding variables, women with dysmenorrhoea had a 2.72 times higher tendency to think of menstruation as a debilitating event than women who did not consider menstruation to be debilitating. The tendency to deny the effects of menstruation in the dysmenorrhoea group was 2.83 times higher than in the non-dysmenorrhoea group; after adjusting for confounding variables, women with dysmenorrhoea had a 2.59 times higher tendency to deny the effects of menstruation. In this study, attitude towards menstruation was related to dysmenorrhoea occurrence. Firat found no significant correlation between menstrual discomfort and attitude towards menstruation. ${ }^{38}$ In that study, 'menstruation is a debilitating event' and 'anticipation and prediction of the onset of menstruation' obtained significantly higher scores from the vocational nursing students with dysmenorrhoea than those who did not have dysmenorrhoea. In terms of 'menstruation is a bothersome event' and 'menstruation is a natural event', the non-dysmenorrhoea group demonstrated significantly higher scores than the dysmenorrhoea group; no significant differences were observed between the two groups in terms of 'denial of any effect of menstruation' ${ }^{26}$ These results are different from those of the present study. The most obvious difference between the two studies is the tendency to deny the effects of menstruation. Scores in the dysmenorrhoea and non-dysmenorrhoea groups in the present study were 23.1 and 26.8, respectively, compared with 26.6 and 28.0 among adolescent nursing students in Firat's study. In other words, compared with adolescent nursing students, the nurses in the present study did not deny the effects caused by menstruation and recognised that they were affected by menstruation. When a nurse experiences dysmenorrhoea, her work may be affected. If she requests menstrual leave, temporary work arrangements must be made and patient care may be affected. Because dysmenorrhoea is a periodic phenomenon, taking frequent menstrual leave may affect working relationships; therefore, nurses usually choose to work even when they experience dysmenorrhoea.

In summary, the factors influencing dysmenorrhoea occurrence included age $<40$ years, working three shift rotations and marital status, and when the mean was used as the contact point, the tendency to consider menstruation to be a debilitating event and the tendency to deny the effects of menstruation were also found to influence dysmenorrhoea. Chiou's study of adolescent nursing students revealed that menstrual regularity and health education were predictive factors for dysmenorrhoea. ${ }^{30}$ Women who had irregular menstrual cycles and had not received dysmenorrhoea related health education demonstrated higher dysmenorrhoea occurrence rates ${ }^{9}$; however, these two factors were not predictive factors in the present study. Our participants were nurses from a wide range of age groups rather than only adolescents; therefore, they had more experience with dysmenorrhoea and self-care. In addition, menstrual health is a part of nursing education; therefore, although nurses are not directly involved in health education, education is part of their professional training. Thus health education was not an important predictive factor in this study. This study mainly evaluated the factors influencing dysmenorrhoea in hospital nurses in order to help institutions build a caring and friendly work environment for high risk nurses. The participants were randomly selected from only two hospitals in southern Taiwan and therefore the results might have limited generalisability to nurses in other parts of the country. In future studies, the inclusion criteria should be extended to examine any differences across regions in Taiwan. In addition, rotating night shifts are required in many other occupations besides nursing. Considering different professional backgrounds and life experiences, future studies should also include women from different occupations who work rotating shifts, to evaluate the differences in the influence of their knowledge and attitudes on the prevalence of dysmenorrhoea. The variables assessed in this study included demographic characteristics, menstruation history, dysmenorrhoea related knowledge and attitudes towards menstruation; however, lifestyle choices, such as smoking, alcohol consumption and exercise, were not included. Further studies that analyse the effects of these lifestyle choices on dysmenorrhoea are warranted.

\section{CONCLUSIONS}

We assessed the various factors influencing the occurrence of dysmenorrhoea with the aim of helping nursing managers to offer appropriate assistance for high risk groups and build a caring and friendly work environment for at risk hospital nurses. These were as follows: (a) setting up a more accommodating working hours system that is based on the nurses' menstrual cycle; (b) creating a supportive workplace environment that allows nurses to take a break from work to apply hot compresses or drink hot beverages; (c) allowing flexible menstrual leave or scheduling menstrual leave, thereby integrating menstrual self-care into the annual occupational safety and health training; and $(\mathrm{d})$ providing spaces at work for nurses to take short breaks and offering supportive measures, such as thermotherapy, aromatherapy massage, and other measures. Such measures will enable nurses to care for themselves at work, thus improving their workplace comfort levels and increasing their work satisfaction and performance.

Acknowledgements The authors thank the participants for their participation, and the nurse managers of the two hospitals for their administrative assistance. We also thank Editage for their professional English review of this manuscript. 
Contributors $\mathrm{M}-\mathrm{HC}$ and $\mathrm{H}-\mathrm{HW}$ designed the study, analysed and interpreted the data, and drafted the manuscript. Y-HY assisted in defining the statistical analysis. $\mathrm{M}-\mathrm{HC}$ and $\mathrm{S}-\mathrm{CH}$ contributed to the data collection and analysis. H-FH and H-MC assisted with drafting the manuscript. All authors had full access to all of the data in the study and take responsibility for its integrity.

Competing interests None declared.

Ethics approval The study was approved by Chi Mei Medical Centre (IRBD No CLH0088).

Provenance and peer review Not commissioned; externally peer reviewed.

Data sharing statement № additional data are available.

Open Access This is an Open Access article distributed in accordance with the Creative Commons Attribution Non Commercial (CC BY-NC 4.0) license, which permits others to distribute, remix, adapt, build upon this work non-commercially, and license their derivative works on different terms, provided the original work is properly cited and the use is non-commercial. See: http://creativecommons.org/ licenses/by-nc/4.0/

(c) Article author(s) (or their employer(s) unless otherwise stated in the text of the article) 2017. All rights reserved. No commercial use is permitted unless otherwise expressly granted.

\section{REFERENCES}

1. Chen CX, Kwekkeboom KL, Ward SE. Beliefs about dysmenorrhea and their relationship to self-management. Res Nurs Health 2016;39:263-76.

2. Eryilmaz G, Ozdemir F. Evaluation of menstrual pain management approaches by Northeastern Anatolian adolescents. Pain Manag Nurs 2009;10:40-7.

3. Kato T. Effects of flexibility in coping with menstrual pain on depressive symptoms. Pain Pract 2017;17:70-7.

4. Zhu X, Wong F, Bensoussan A, et al. Are there any cross-ethnic differences in menstrual profiles? A pilot comparative study on Australian and Chinese women with primary dysmenorrhea. J Obstet Gynaecol Res 2010;36:1093-101.

5. Abdul-Razzak KK, Ayoub NM, Abu-Taleb AA, et al. Influence of dietary intake of dairy products on dysmenorrhea. $J$ Obstet Gynaecol Res 2010;36:377-83.

6. Agarwal AK, Agarwal A. A study of dysmenorrhea during menstruation in adolescent girls. Indian J Community Med 2010;35:159-64.

7. Loto OM, Adewumi TA, Adewuya AO. Prevalence and correlates of dysmenorrhea among Nigerian college women. Aust N Z J Obstet Gynaecol 2008;48:442-4.

8. Chang YT, Chen YC. Menstrual health care behavior and associated factors among female elementary students in the Hualien region. J Nurs Res 2008;16:8-16.

9. Chiou MH, Wang HH. Predictors of dysmenorrhea and self-care behavior among vocational nursing school female students. J Nurs Res 2008;16:17-25.

10. Cheng HF, Lin YH. Selection and efficacy of self-management strategies for dysmenorrhea in young Taiwanese women. J Clin Nurs 2011;20:1018-25.

11. Palmer D. "To help a million sick, you must kill a few nurses": nurses' occupational health, 1890-1914. Nurs Hist Rev 2012;20:14-45.

12. Laschinger HK, Grau AL. The influence of personal dispositional factors and organizational resources on workplace violence, burnout, and health outcomes in new graduate nurses: a cross-sectional study. Int J Nurs Stud 2012;49:282-91.

13. Payne LA, Rapkin AJ, Lung KC, et al. Pain catastrophizing predicts menstrual pain ratings in adolescent girls with chronic pain. Pain Med 2016;17:16-24.

14. Berkley KJ, McAllister SL. Don't dismiss dysmenorrhea!. Pain 2011;152:1940-1.
15. Chiu MH, Wang HH, Hsu SC, et al. Dysmenorrhoea and self-care behaviours among hospital nurses: a questionnaire survey. J Clin Nurs 2013;22:3130-40.

16. Wong LP. Attitudes towards dysmenorrhoea, impact and treatment seeking among adolescent girls: a rural school-based survey. Aust $J$ Rural Health 2011;19:218-23.

17. Zukr SM, Naing L, Hamzah TNT, et al. Primary dysmenorrhea among medical and dental university students in Kelantan: prevalence and associated factors. Int Med J 2009;16:93-9.

18. I-C Lu. Dysmenorrhea and related factors in Taiwanese adolescent girls. Austin, USA: University of Texas at Austin, 2010.

19. Chang $\mathrm{C}$, Chen $\mathrm{FL}$, Chang $\mathrm{CH}$, et al. A preliminary study on menstrual health and menstrual leave in the workplace in Taiwan. Taiwan J Public Health 2011;30:436-50.

20. Schluter PJ, Turner $C$, Huntington AD, et al. Work/life balance and health: the nurses and midwives e-cohort study. Int Nurs Rev 2011;58:28-36.

21. Cady RK, Diamond ML, Diamond MP, et al. Sumatriptan-naproxen sodium for menstrual migraine and dysmenorrhea: satisfaction, productivity, and functional disability outcomes. Headache 2011:51:664-73.

22. Bettendorf B, Shay S, Tu F. Dysmenorrhea: contemporary perspectives. Obstet Gynecol Surv 2008;63:597-603.

23. Perry M. Treatment options for dysmenorrhoea. Practice Nurs 2012;23:195-8.

24. Ju H, Jones M, Mishra GD. Smoking and trajectories of dysmenorrhoea among young Australian women. Tob Control 2016;25:195-202.

25. Chiou $\mathrm{MH}$, Wang $\mathrm{HH}$. [The relationship between dysmenorrhea and menstrual attitudes among female students in vocational nursing schools]. Hu Li Za Zhi 2004;51:45-52.

26. Parker MA, Sneddon AE, Arbon P. The menstrual disorder of teenagers (MDOT) study: determining typical menstrual patterns and menstrual disturbance in a large population-based study of Australian teenagers. BJOG 2010;117:185-92.

27. Stubbs ML. Cultural perceptions and practices around menarche and adolescent menstruation in the United States. Ann N Y Acad Sci 2008;1135:58-66.

28. Cheng CY, Yang K, Liou SR. Taiwanese adolescents' gender differences in knowledge and attitudes towards menstruation. Nurs Health Sci 2007;9:127-34.

29. Ly H. The medical utilization of chinese and western medicine in females with dysmenorrhea. Taiwan: Kaohsiung Medical University, 2012.

30. Chiou $\mathrm{MH}$, Wang $\mathrm{HH}$, Yang $\mathrm{YH}$. Effect of systematic menstrual health education on dysmenorrheic female adolescents' knowledge, attitudes, and self-care behavior. Kaohsiung J Med Sci 2007:23:183-90.

31. Brooks-Gunn J, Ruble DN. The menstrual attitude questionnaire. Psychosom Med 1980;42:503-12.

32. Prevalence and associated factors of premenstrual syndrome among nurses in Taiwan. Taiwan: Ministry of Science and Technology, ROC, 1994.

33. Morrison LA, Larkspur L, Calibuso MJ, et al. Women's attitudes about menstruation and associated health and behavioral characteristics. Am J Health Behav 2010;34:90-100.

34. Lo Sing-Kai LC-F. On the use and interpretation of Cronbach's alpha. J Nurs Res 1998;6:82-9.

35. Lin YX. When "Experts" meet the medical professionals: the women with menstrual pain encountering western medicine. Taiwan: Kaohsiung Medical University, 2006.

36. Chung FF, Yao CC, Wan GH. The associations between menstrual function and life style/working conditions among nurses in Taiwan. J Occup Health 2005;47:149-56.

37. Takeuchi H, Oishi T, Harada T. Morningness-eveningness preference, and mental and physical symptoms during the menstrual cycle of Japanese junior high school students. Sleep Biol Rhythms 2003;1:245-7.

38. Firat MZ, Kulakaç $\mathrm{O}$, Oncel S, et al. Menstrual attitude questionnaire: confirmatory and exploratory factor analysis with Turkish samples. $J$ Adv Nurs 2009;65:652-62. 